\title{
Epidemiology of Acne Vulgaris and Its Association With Lifestyle Among Adolescents and Young Adults in Hail, Kingdom of Saudi Arabia: A Community-Based Study
}

Fawwaz F. Alshammrie ${ }^{1}$, Rasha Alshammari ${ }^{2}$, Renad M. Alharbi ${ }^{2}$, Farida Habib Khan ${ }^{3}$, Saud K. Alshammari ${ }^{2}$

1. Medicine, University of Hail, Hail, SAU 2. Medicine and Surgery, College of Medicine, University of Hail, Hail, SAU 3. Community Medicine, College of Medicine, University of Hail, Hail, SAU

Corresponding author: Fawwaz F. Alshammrie, fawwzf@yahoo.com

\begin{abstract}
Acne vulgaris is the commonest dermatological problem internationally and nationally. Its incidence is increasing every year in the Kingdom of Saudi Arabia (KSA). Though it is not a major health issue but it significantly affects the patient cosmetically, psychologically and socially. Previous studies have shown its association with lifestyle (age, diet, stress, sleep, smoking, exercise, obesity, etc.) and family history. By simple cost-effective lifestyle modification, its occurrence and late consequences could be minimized. Few hospital-based studies are done on this issue in Hail City, KSA. Hence present cross-sectional study was designed where data was collected by Google-Form from 484 residents of Hail City. Results have revealed that $65 \%$ of our respondents were suffering from mild to moderate Acne. Thirty percent of the respondents had BMI equal to more than 30 . Majority of respondents ( $81 \%$ ) had acne on whole face. Similarly, dairy products were also consumed by more than $50 \%$. Majority of respondents (more than $50 \%$ ) took chocolates, fast foods, oily foods and sea-foods. Nuts were taken quite often by $37 \%$ of respondents. Age between $21-25$ years and oily skin have a highly significant association $(p=0.000)$ with development of acne. Other variables that show significant association with acne were being obese, stressful, irregular menstrual cycles and excessive intake of nuts.
\end{abstract}

Hence there is a need to address this issue in order to design recommendations for the general public to minimize the incidence and consequences of acne vulgaris by simple lifestyle modifications.

Received 06/21/2020

Review began $07 / 02 / 2020$ Review ended 07/08/2020 Published 07/19/2020

\section{() Copyright 2020}

Alshammrie et al. This is an open access article distributed under the terms of the Creative Commons Attribution License CC-BY 4.0., which permits unrestricted use, distribution, and reproduction in any medium, provided the original author and source are credited.
Categories: Dermatology

Keywords: acne vulgaris, epidemiology, lifestyle

\section{Introduction}

Acne vulgaris is the eighth most prevalent disease globally. Previous studies have found the prevalence of acne vulgaris $9.4 \%$ worldwide $[1,2]$. The manifestations of acne may range from very mild lesions, called physiologic acne, to very severe findings in the form of abscess formation [3]. A study done in Hail, Kingdom of Saudi Arabia (KSA) in the period 2008-2014 for five years found that $20 \%$ of patients attending a dermatology clinic complain of acne vulgaris as compared to $12.43 \%$ acne cases in the same hospital, King Khalid Hospital, in the period from 1995 to 1997 [4,5]. This reflects that the incidence of acne vulgaris is increasing in the Kingdom. Another study conducted in a nearby region of Northern Saudi Arabia, Arar, revealed $54 \%$ prevalence of acne among adolescents $[6,7]$.

Previous studies investigating the potential link between lifestyle and acne vulgaris have shown controversial results [8]. Moreover, literature review suggested that its prevalence varies with several genetic and environmental factors. A study done by Ballanger et al. found a strong association of causation of acne vulgaris to both genetic and environmental elements $[9,10]$. Positive family history of acne vulgaris is associated with severe form of acne manifestations, in addition to early onset of pre-pubertal acne [9]. Prevalence of moderate to severe acne among those having positive family history was $20 \%$ as compared to $10 \%$ in those lacking a family history of acne [10-12]. Further it is found by studies that severity of acne is strongly associated with positive family history [13].

Since early 1900s, the association between acne and dietary habits has been questioned in the literature [14]. Literature showed enough epidemiological link to consider the effect of diet on acne [6,7]. Hence, studies have suggested dermatologists to encourage patients with acne to avoid refined carbohydrates and shift to low glycemic index foods [8]. Recent change in lifestyle globally and its effect on diet has ultimately affected body mass index that is linked to increase the prevalence and severity of acne [10-12].

Although it is not a major health issue, but it can significantly affect patient cosmetically, psychosocially and socially. Moreover, causing a substantial impact on the quality of life. Limited studies have been done 
on acne in Hail region with no previous community-based studies investigating the epidemiology and the disease profile thoroughly, necessitating the need for this issue to be addressed in order to achieve a better understanding of this disease, thereby leading to a positive patient outcome.

Further as the previous studies report increasing prevalence of acne vulgaris during the past two decades in KSA; present study was done to assess the association of acne vulgaris with epidemiological factors (such as age, diet, stress, sleep, smoking, exercise, obesity, etc.) by conducting a community-based survey, as the previous studies done in Hail, were all hospital based.

\section{Materials And Methods Objectives}

The objectives of this study are: to study the epidemiology of acne vulgaris and its association with lifestyle among adolescents and young adults in Hail, Kingdom of Saudi Arabia; to estimate the prevalence of acne vulgaris among adolescents and young adults in Hail; to describe the pattern of acne vulgaris among adolescents and young adults in Hail; to investigate the association of acne vulgaris with lifestyle, including diet, exercise, sleep, skin care products, and related risk factors; to list the risk factors predisposing to acne vulgaris among adolescents and young adults in Hail; to describe different management strategies for acne vulgaris used by adolescents and young adults in Hail.

\section{Subjects and methods}

Hail City is located in northwest of KSA; the city has a population of 400,000 . This study was planned in the mid of year 2019. In September 2019, proposal was approved by IRB (Institutional Review Board) of University of Hail. A descriptive cross-sectional community-based study was done in Hail City between 15th of December 2019 and 15th of January 2020. A structured questionnaire was designed and translated in Arabic language. Researchers used RaoSoft, an online calculator, to estimate sample size. Minimum effective sample size came out to be 384, calculated at the confidence interval of 95\% (RaoSoft, 2013). However, researchers were successful in achieving sample size of 484 .

It was pretested on 10 randomly selected people. Purpose of this pilot testing was to assess the clarity of question and identify any ambiguous or lengthy questions, in addition to testing its applicability. It was then fed on Google Form. Link was sent to 500 residents of Hail City through a variety of websites and apps. But there were 484 responses. The objectives of the study were explained on the first page of Google Form. Their participation reflected their consent for the study.

The questionnaire consisted of 32 close-ended questions. The questionnaire included six important domains: socio-demographic data, presence of acne and pattern, lifestyle and coexisting pathologic factors or diseases, specific risk factors, and management strategies, that were used including both medical and home remedies. Questions about socio-demographic data included age, sex, weight, height, nationality, residence, and level of education. The prevalence and pattern of acne was investigated using subjective questions about presence of acne, family history, severity, pattern, coexisting chronic disease, and management. Moreover, there were questions targeting specific lifestyle behaviors such as smoking, sleeping hours, and physical activity. In addition, there were questions about events aggravating acne, skin care products and skin hygiene, and diet.

Data was entered and analyzed by Statistical Package for Social Sciences (SPSS) version 23 (IBM Corp., Armonk, NY). Descriptive analysis was done showing frequency and percentages. For analytical analysis, chi-square test was applied keeping the level of significance (p-value) $<0.05$.

\section{Results}

Figure 1 shows age of respondents in range of five years interval. Most of the respondents $(181 / 484=37.4 \%)$ were of the age group between 21-25 years. 


\section{Cureus}

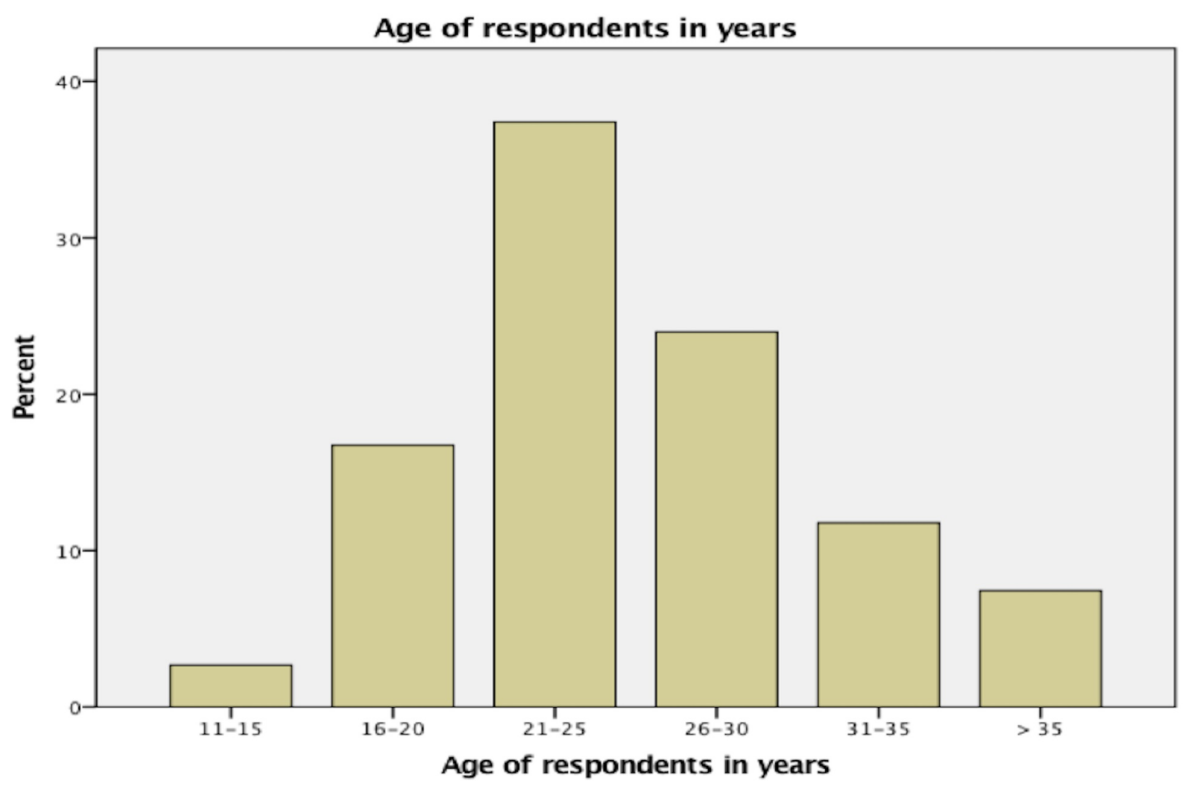

FIGURE 1: Age of respondents in years

Other demographic variables of respondents are shown in Table 1. Most of the respondents (84\%) were females. Thirty-eight percent had body mass index (BMI) equal to more than 30. Most of the respondents were Saudis (98\%) and residents of Hail City (93\%). Seventy-six percent were qualified Bachelors. Table 2 shows that most of the respondents (53\%) had combination of oily and dried skin, facial cleanser was used 34 times/week by $30 \%$ of respondents while majority $(71 \%)$ did not use any sun-block cream. Ninety-one percent did not have any chronic disease (91\%) and were non-smokers (94\%). No sort of any physical exercise is being practiced by $56 \%$, though almost the same percentage (50\%) had enough sleep span of 7-9 hours/day. Among the female respondents, majority (68\%) had irregular menstrual cycles. 


\section{Cureus}

\begin{tabular}{|c|c|c|}
\hline Variable & Frequency & Percentage \\
\hline \multicolumn{3}{|l|}{ Gender: } \\
\hline Male & 76 & 16 \\
\hline Female & 408 & 84 \\
\hline \multicolumn{3}{|l|}{ BMI: } \\
\hline$<24.9$ & 174 & 36 \\
\hline $25-29.9$ & 125 & 26 \\
\hline$\geq 30$ & 185 & 38 \\
\hline \multicolumn{3}{|l|}{ Nationality: } \\
\hline Saudi & 475 & 98 \\
\hline Non-Saudi & 09 & 02 \\
\hline \multicolumn{3}{|l|}{ City of Residence: } \\
\hline Hail & 440 & 93 \\
\hline Other than Hail & 35 & 07 \\
\hline \multicolumn{3}{|l|}{ Educational Level: } \\
\hline School & 02 & 0.4 \\
\hline Middle School & 12 & 2.6 \\
\hline High School & 89 & 18 \\
\hline Bachelors & 367 & 76 \\
\hline Masters or Doctorate & 14 & 03 \\
\hline
\end{tabular}

TABLE 1: Demographic profile of respondents $(n=484)$ 


\section{Cureus}

\begin{tabular}{|c|c|c|}
\hline Variable & Frequency & Percentage \\
\hline \multicolumn{3}{|l|}{ Skin Type: } \\
\hline Oily & 149 & 31 \\
\hline Dry & 79 & 16 \\
\hline Combination & 256 & 53 \\
\hline \multicolumn{3}{|c|}{ Frequency of using facial cleanser: } \\
\hline Never & 113 & 23 \\
\hline 1-2 times/week & 124 & 25 \\
\hline 3-4 times/week & 144 & 30 \\
\hline 1-2 times/day & 105 & 22 \\
\hline \multicolumn{3}{|l|}{ Sun-Block Cream: } \\
\hline Regular user & 140 & 29 \\
\hline Do not use & 344 & 71 \\
\hline \multicolumn{3}{|l|}{ Chronic Disease: } \\
\hline Yes, have & 43 & 09 \\
\hline Do not have & 441 & 91 \\
\hline \multicolumn{3}{|l|}{ Smoking: } \\
\hline Yes & 26 & 05 \\
\hline No & 453 & 94 \\
\hline Ex-smoker & 05 & 01 \\
\hline \multicolumn{3}{|c|}{ Physical Exercise (hours/week): } \\
\hline Never & 270 & 56 \\
\hline 1-2 times & 135 & 28 \\
\hline 3-4 times & 50 & 10 \\
\hline Every day & 29 & 06 \\
\hline \multicolumn{3}{|l|}{ Sleep (hours/day): } \\
\hline Less than 5 & 32 & 07 \\
\hline $5-7$ & 61 & 13 \\
\hline 7-9 & 240 & 50 \\
\hline More than 9 & 151 & 13 \\
\hline \multicolumn{3}{|c|}{ Menstrual Cycle ( $n=408$ females): } \\
\hline Regular & 129 & 32 \\
\hline Irregular & 279 & 68 \\
\hline NA (male-respondents) & 76 & \\
\hline
\end{tabular}

TABLE 2: Personal information of respondents $(n=484)$

As shown in Table 3, 65\% (316/484) of our respondents were suffering from mild to moderate acne. Out of them, majority (81\%) had acne on whole face. Majority (57\%) was applying topical ointments. Seventy-four percent of respondents had mainly mothers and sisters affected by acne. Table 4 reveals that majority (72\%) 


\section{Cureus}

of the respondents had the knowledge that stress, fatigue, tension are the main causes of acne followed by hormonal abnormality, application of oily creams and cosmetics. Sixty percent answered that acne is a hereditary skin problem, though excessive sweating, obesity, closed-pores and improper cleaning of skin were also marked as causative factors by majority (Table 5). Majority of respondents (70\%) had the opinion that fried foods and chips aggravate acne (Table 5).

\begin{tabular}{|c|c|c|}
\hline Variable & Frequency & Percentage \\
\hline \multicolumn{3}{|l|}{ Having Acne $(n=484)$ : } \\
\hline Yes & 316 & 65 \\
\hline No & 168 & 35 \\
\hline \multicolumn{3}{|l|}{ Site of Acne $(n=316)$ : } \\
\hline Whole face & 277 & 81 \\
\hline Whole face with chest & 21 & 13 \\
\hline Whole face with chest and back & 09 & 03 \\
\hline Face with chest, back and upper arm & 09 & 03 \\
\hline \multicolumn{3}{|l|}{ Severity of your acne ( $n=316)$ : } \\
\hline Mild & 121 & 38 \\
\hline Moderate & 135 & 43 \\
\hline Severe & 60 & 19 \\
\hline \multicolumn{3}{|l|}{ Visited any doctor for acne $(n=316)$ : } \\
\hline Yes & 200 & 63 \\
\hline No & 136 & 37 \\
\hline \multicolumn{3}{|l|}{ Treatment for acne ( $n=316)$ : } \\
\hline Oral medication & 50 & 16 \\
\hline Topical medication & 181 & 57 \\
\hline Face wash & 50 & 16 \\
\hline None & 35 & 11 \\
\hline \multicolumn{3}{|c|}{ Any family member affected with acne $(n=316)$ : } \\
\hline Yes & 234 & 74 \\
\hline No & 82 & 26 \\
\hline \multicolumn{3}{|l|}{ If yes, what is your relation? $(\mathrm{n}=234)$} \\
\hline Father & 10 & 04 \\
\hline Mother & 56 & 24 \\
\hline Sibling & 155 & 66 \\
\hline Own children & 13 & 06 \\
\hline
\end{tabular}

\section{TABLE 3: Information regarding respondents' acne}




\section{Cureus}

\begin{tabular}{lll} 
Variable & Frequency & Percentage \\
Stress \& Fatigue: & 350 & 72 \\
Yes & 110 & 23 \\
No & 24 & 05 \\
I do not know & & \\
Hormonal Abnormality: & 301 & 62 \\
Yes & 18 & 04 \\
No & 165 & 34 \\
I do not know & & \\
Scalp Oil or Bleaching Cream: & 288 & 60 \\
Yes & 186 & 38 \\
No & 10 & 02 \\
I do not know & & 55 \\
Cosmetics: & 263 & 42 \\
Yes & 201 & 03 \\
No & 20 & 55 \\
I do not know & & \\
\hline
\end{tabular}

TABLE 4: Relationship of acne with certain variables $(n=484)$ 


\section{Cureus}

\begin{tabular}{|c|c|c|}
\hline Variable & Frequency & Percentage \\
\hline \multicolumn{3}{|l|}{ Conditions that aggravate acne: } \\
\hline Not cleaning the skin properly & 145 & 30 \\
\hline Constant exposure to sunlight and humidity & 121 & 25 \\
\hline Exercise/excessive sweatıng & 08 & 40 \\
\hline Hijab border sites & 01 & 05 \\
\hline Lack of sleep & 06 & 28 \\
\hline Removal of hair by wax or shave & 92 & 19 \\
\hline Closed pores & 145 & 30 \\
\hline Obesity & 08 & 40 \\
\hline Hereditary & 290 & 60 \\
\hline \multicolumn{3}{|l|}{ roods that aggravate acne: } \\
\hline Fatty food and butter & 145 & 30 \\
\hline Chocolate & 218 & 45 \\
\hline Dairy products & 242 & 50 \\
\hline Soft drinks & 145 & 30 \\
\hline Fried food or chips & 339 & 70 \\
\hline
\end{tabular}

TABLE 5: Aggravating factors for acne $(n=484)$ (more than one options were selected by respondents)

Dietary habit of those who had acne is shown in Table 6. Majority of them used to drink whole milk 3-4 times/week. Similarly, dairy products were also consumed by the same frequency. Majority of them took twice a week fruit, fruit juices and vegetables. Chocolates, fast foods, oily foods and sea-foods were also taken by the same frequency by the respondents. Nuts were taken quite often by $37 \%$ of respondents. 


\section{Cureus}

\begin{tabular}{|c|c|c|c|}
\hline \multicolumn{2}{|l|}{ Variable } & \multirow{2}{*}{$\begin{array}{l}\text { Frequency } \\
09\end{array}$} & \multirow{2}{*}{$\begin{array}{l}\text { Percentage } \\
03\end{array}$} \\
\hline Milk: & Never & & \\
\hline & 1-2 times/week & 126 & 40 \\
\hline & 3-4 times/week & 101 & 32 \\
\hline & 1-2 times/day & 74 & 25 \\
\hline \multirow[t]{2}{*}{ Type of milk: } & Whole & 245 & 78 \\
\hline & Skimmed & 71 & 22 \\
\hline \multirow[t]{4}{*}{ Dairy Product: } & Never & 06 & 02 \\
\hline & 1-2 times/week & 91 & 28 \\
\hline & 3-4 times/week & 119 & 38 \\
\hline & Every day & 100 & 32 \\
\hline \multirow[t]{4}{*}{ Fruits: } & Never & 06 & 02 \\
\hline & 1-2 times/week & 290 & 92 \\
\hline & 3-4 times/week & 10 & 03 \\
\hline & Every day & 10 & 03 \\
\hline \multirow[t]{4}{*}{ Vegetables: } & Never & 11 & 04 \\
\hline & 1-2 times/week & 182 & 03 \\
\hline & 3-4 times/week & 113 & 57 \\
\hline & Every day & 10 & 36 \\
\hline \multirow[t]{4}{*}{ Sea Food: } & Never & 46 & 15 \\
\hline & 1-2 times/week & 180 & 57 \\
\hline & 3-4 times/week & 80 & 25 \\
\hline & Every day & 10 & 03 \\
\hline \multirow[t]{4}{*}{ Chocolate: } & Never & 14 & 04 \\
\hline & 1-2 times/week & 119 & 37 \\
\hline & 3-4 times/week & 83 & 26 \\
\hline & Every day & 100 & 33 \\
\hline \multirow[t]{4}{*}{ Nuts: } & Never & 20 & 06 \\
\hline & 1-2 times/week & 128 & 41 \\
\hline & 3-4 times/week & 118 & 37 \\
\hline & Every day & 50 & 16 \\
\hline \multirow[t]{4}{*}{ Oily Food: } & Never & 28 & 09 \\
\hline & 1-2 times/week & 142 & 45 \\
\hline & 3-4 times/week & 120 & 38 \\
\hline & Every day & 26 & 08 \\
\hline
\end{tabular}

TABLE 6: Dietary history of respondents who had acne $(n=316)$

Table 7 reveals association of occurrence of acne with certain variables. Here age between 21-25 years and oily skin have a highly significant association $(\mathrm{p}=0.000)$ with development of acne. Other variables that 
showed significant association with acne are being obese, smoker, stressful, irregular menstrual cycles and excessive intake of nuts.

\begin{tabular}{|l|l|}
\hline Comparing Variable & Occurrence of Acne \\
\hline Age between $21-25$ years & p-value \\
\hline BMI ( $\geq 30)$ & 0.000 \\
\hline Skin Type (Oily) & 0.005 \\
Smoking & 0.000 \\
\hline Being Stressful & 0.003 \\
\hline Intake of Dairy Products & 0.040 \\
\hline Intake of Chocolates & 0.913 \\
Doing Physical Exercise & 0.099 \\
Irregular Menstruation & 0.917 \\
\hline Intake of Fast Food & 0.027 \\
\hline Excessive Intake of Nuts & 0.171 \\
\hline
\end{tabular}

TABLE 7: Association of occurrence of acne with certain variables (chi-square test considering level of significance $\leq \mathbf{0 . 0 5}$ )

\section{Discussion}

Acne vulgaris is a common chronic skin disease involving blockage of and/or inflammation of pilosebaceous units. This study was conducted to determine the epidemiology of acne vulgaris and its association with lifestyle among adolescents and young adults. In the current study, the age group of the participants ranged from 10 to 35 years. Before discussion of our results, limitations of the study include the cross-sectional design, which makes interpretation of causality difficult, and the use of self-reported data on BMI and acne, which can allow for measurement errors.

The prevalence of acne in this study was found to be $65 \%$ among adolescents and young adults in Hail, Saudi Arabia. Highly significant association was found $(p$-value $=0.000)$ between acne occurrence and age between 21-25 years. Similar results were reported in a study conducted in Jeddah, Saudi Arabia, which found that overall prevalence of acne among males and females was 64.5\% [15]. Also, we are in accordance with another study that was conducted in Central Saudi Arabia which showed that $56.2 \%$ of the university students had acne [16]. In addition, we are in accordance with similar study that was conducted in the Northern region of Saudi Arabia, which reported that the prevalence of acne vulgaris was 53.5\% among adolescent male students [6]. There is uniformity in the rates reported in recent studies regardless of the variation of the assessment tools used. Our results are much higher than the results reported in an Australian study which reported that overall prevalence of acne among male and female participants was 36.1\% [17]. In addition, our results are slightly higher than the results of a study in Makkah, Saudi Arabia, which found the prevalence of acne among teenage females was 45.7\% [18]. However, our findings are much lower than the findings of a study in Tehran where the overall prevalence of acne was $93.2 \%, 94.4 \%$ for boys and $92.0 \%$ for girls [13]. The very high rate of acne vulgaris in Iranian adolescents could be explained by genetic predisposition, their skin nature has a tendency to develop acne, certain nutrition habits in the society that increase formation of acne. Also, the study population had pupils aged $16+/-0.9$ years, which is the highest affected group due to increase sebaceous glands activity in this age. However, the high prevalence in our study may be due to the fact that our study was conducted on adolescents and young adults and these age groups are more commonly affected by acne.

Moreover, the difference in prevalence rates between these studies might be affected by different diagnostic criteria. In this study, the prevalence of respondents who had BMI $>30$ was $38 \%$ and there was significant association ( $p$-value $=0.005$ ) between occurrence of acne and high BMI. Few and controversial data are available concerning the relationship between BMI and acne. Similar results in a study conducted in Taiwan among schoolchildren (aged 6-11 years), reported the mean BMI in students with acne was much higher than that of unaffected students with no specific gender preference [19]. In addition, in a study conducted in Saudi Arabia among women with polycystic ovary syndrome, acne was associated with overweight and 
obesity [20]. Also, we are in accordance with a study conducted in Eastern Saudi Arabia among obese female schoolchildren which reported that the prevalence of acne in the obese was $30.9 \%$ [21].

It was hypothesized that obesity can cause peripheral hyperandrogenism, which may lead to increased sebum production and the development of severe acne. On the contrary, a study conducted in the United Kingdom within the Glasgow Alumni Cohort found no any association between acne and BMI [22]. Conversely, a study conducted in Taiwan investigating the impact of obesity on cutaneous manifestations of clinical hyperandrogenism, found that obese women had less acne than nonobese subjects, although BMI had a significant positive correlation with serum total testosterone [23]. Our data show a main protective effect on the appearance of acne from lower BMI values. The prevalence of skin type in this study was oily (31\%), dry (16\%) and combination (53\%). Our study showed highly significant association (p-value $=0.000$ ) between oily skin and acne.

Another study conducted among adolescents and young females in Arar, Saudi Arabia showed the prevalence of greasy skin among acne patients was $72.7 \%$ and dry skin was $27.3 \%$ [6]. In addition, a study was done among acne patients in a suburban population that found the prevalence of oily skin was $61.4 \%$ and there is a relation between severity of acne and oiliness [24]. Kulthanan et al. reported two-thirds of acne patients to have oily skin [25]. The association between acne and oily skin may be explained by increased sebum secretion and it is a major concurrent event associated with the development of acne.

There are few studies about relationship between acne and smoking. Smoking can lead to adverse effects on the skin due to alterations in the skin microcirculation, keratinocytes, and collagen and elastin synthesis. Smoking could cause alteration in sebum composition through decrease antioxidants. We found significant association ( $p$-value $=0.003$ ) between smoking and appearance of acne. Similar results in a study conducted in Italy showed a correlation between smoking and acne [26]. On the contrary, a study done in Italy among adolescents and young adults showed no association between smoking and acne [10]. There are not enough studies that investigated the relationship between acne and physical activity. In this study, there is no significant association ( $\mathrm{p}$-value $=0.913$ ) between doing physical exercise and acne. In agreement with a study conducted in Tehran, it reported no association between physical activity and acne [13]. Hormonal factors play a role in acne development, but few studies have been done to analyze the role of menstrual history on the risk of acne. We found significant association ( $p$-value $=0.027$ ) between menstrual disturbance and acne. We are in accordance with a study conducted in Makkah that showed association between irregular menstruation and acne as $80 \%$ of acne patients had menstrual disturbance [18]. Conversely, a study conducted in Italy reported no relationship between menstrual pattern and acne [10]. Also, a large scale twins study conducted in the United Kingdom showed no relationship between acne and reproductive or hormonal potential risk factors [27]. As when we asked about the severity of the participants' acne $43 \%$ reported it as moderate severity, and $38.9 \%$ as mild which correlate with Alfalogy study as they display $38 \%$ were moderate in females and 30\% were mild [18]. Similarly, in another study aimed to evaluate the effect of practice toward lifestyle in adolescence it showed 70 students out of 148 had variable degrees of severity and the overall was 47.3\% [28]. Participants' knowledge of the relation between acne and stress is really impressing (72\%) with significant p-value $=0.040$. While $58 \%$ thought that stress would make acne worse in Jeddah study but with no significant value [15]. Another study emphasizes that stress is a risk factor for acne with p-value of $<0.001$ and almost $82 \%$ of participants [18]. Dairy products are thought to aggravate acne, however, the participants' response was 30\% with no significance, 38\% took it 3 or 4 times/week and the majority took the whole milk (78\%). While a study in Italy showed that milk products increase the risk of acne especially skim milk more than the whole milk [10]. Also, Al Hussein et al.'s study showed that milk has no effect on acne with p-value of 0.938 [28].

\section{Conclusions}

This study was focused on Hail population in Saudi Arabia to reveal the prevalence of acne vulgaris, and it found that more than half of participants had acne in the age between 21-25 which is an increase in the incidence of the disease and it is worrisome. More workup is needed now for assessing the cause, the level of awareness, and addressing more risk factors to draw attention on the necessity for the development of effective intervention program with multidisciplinary teams (dermatologist, health educator, psychologist, social worker, and physical trainer) working in harmony to control, reduce, and properly manage the burden of the disease.

This program should include a comprehensive school-based acne education program, and a university-based acne education program should be considered for acne vulgaris students and their parents to improve the awareness about young adulthood acne disease. Meanwhile, determining most causative agents for adults and young adults will help dermatologist to educate the patients regarding environmental modification.

\section{Additional Information \\ Disclosures}

Human subjects: All authors have confirmed that this study did not involve human participants or tissue. Animal subjects: All authors have confirmed that this study did not involve animal subjects or tissue. 
Conflicts of interest: In compliance with the ICMJE uniform disclosure form, all authors declare the following: Payment/services info: All authors have declared that no financial support was received from any organization for the submitted work. Financial relationships: All authors have declared that they have no financial relationships at present or within the previous three years with any organizations that might have an interest in the submitted work. Other relationships: All authors have declared that there are no other relationships or activities that could appear to have influenced the submitted work.

\section{References}

1. Vos T, Flaxman AD, Naghavi M, et al.: Years lived with disability (YLDs) for 1160 sequelae of 289 diseases and injuries 1990-2010: a systematic analysis for the Global Burden of Disease Study 2010. The Lancet. 2012, 380:2163-2196. 10.1016/S0140-6736(12)61729-2

2. Hay RJ, Johns NE, Williams HC, et al.: The global burden of skin disease in 2010: an analysis of the prevalence and impact of skin conditions. J Invest Dermatol. 2014, 134:1527-1534. 10.1038/jid.2013.446

3. Degitz K, Placzek M, Borelli C, Plewig G: Pathophysiology of acne (Article in German) . J Dtsch Dermatol Ges. 2007, 5:316-323. 10.1111/j.1610-0387.2007.06274.x

4. Al Shammrie F, Al Shammrie A: Pattern of skin disease in Hail region of Saudi Arabia . J Dermatol Dermatol Surg. 2017, 21:62-65. 10.1016/j.jdds.2017.04.001

5. Parthasaradhi A, Al Gufai AF: The pattern of skin diseases in Hail region, Saudi Arabia . Ann Saudi Med. 1998, 18:558-561. 10.5144/0256-4947.1998.558

6. Abo El-Fetoh NM, Alenezi NG, Alshamari NG, Alenezi OG: Epidemiology of acne vulgaris in adolescent male students in Arar, Kingdom of Saudi Arabia. J Egyptian Public Health Assoc. 2016, 91:144-149. 10.1097/01.EPX.0000492401.39250.62

7. Alanazi MS, Hammad SM, Mohamed AE: Prevalence and psychological impact of Acne vulgaris among female secondary school students in Arar city, Saudi Arabia, in 2018. Electron Physician. 2018, 10:72247229. 10.19082/7224

8. Mahmood SN, Bowe WP: Diet and acne update: carbohydrates emerge as the main culprit . J Drugs Dermatol. 2014, 13:428-435.

9. Ballanger F, Baudry P, N'Guyen J, Khammari A, Dréno B: Heredity: a prognostic factor for acne . Dermatology. 2006, 212:145-149. 10.1159/000090655

10. Di Landro A, Cazzaniga S, Parazzini F, et al.: Family history, body mass index, selected dietary factors, menstrual history, and risk of moderate to severe acne in adolescents and young adults. J Am Acad Dermatol. 2012, 67:1129-1135. 10.1016/j.jaad.2012.02.018

11. Berra B, Rizzo AM: Glycemic index, glycemic load, wellness and beauty: the state of the art . Clin Dermatol 2009, $27: 230-235.10 .1016 / j$.clindermatol.2008.04.006

12. Fiedler F, Stangl GI, Fiedler E, Taube K-M: Acne and nutrition: a systematic review. Acta Derm Venereol. 2017, 97:7-9. 10.2340/00015555-2450

13. Ghodsi SZ, Orawa H, Zouboulis CC: Prevalence, severity, and severity risk factors of acne in high school pupils: a community-based study. J Invest Dermatol. 2009, 129:2136-2141. 10.1038/jid.2009.47

14. Campbell GG: The relation of sugar intolerance to certain diseases of the skin . Br J Dermatol. 1931, 43:297304.

15. Al Mashat S, Al Sharif N, Zimmo S: Acne awareness and perception among population in Jeddah, Saudi Arabia. J Saudi Soc Dermatol Dermatol Surg. 2013, 17:47-49. 10.1016/j.jssdds.2013.05.003

16. Al Robaee AA: Prevalence, knowledge, beliefs and psychosocial impact of acne in University students in Central Saudi Arabia. Saudi Med J. 2005, 26:1958-1961.

17. Stathakis V, Kilkenny M, Marks R: Descriptive epidemiology of acne vulgaris in the community . Australas J Dermatol. 1997, 38:115-123. 10.1111/j.1440-0960.1997.tb01126.x

18. Alfalogy EH: Epidemiology of acne vulgaris: prevalence, severity and its impact among school teenagers in Makkah, Saudi Arabia. Egyptian Family Med J. 2018, 2:1-12. 10.21608/EFMJ.2018.67775

19. Tsai M-C, Chen W, Cheng Y-W, Wang C-Y, Chen G-Y, Hsu T-J: Higher body mass index is a significant risk factor for acne formation in schoolchildren. Eur J Dermatol. 2006, 16:251-253.

20. Tamimi W, Siddiqui IA, Tamim H, AlEisa N, Adham M: Effect of body mass index on clinical manifestations in patients with polycystic ovary syndrome. Int J Gynecol Obstet. 2009, 107:54-57. 10.1016/j.ijgo.2009.06.003

21. Al-Saeed WY, Al-Dawood KM, Bukhari IA, Bahnassy A: Dermatoses in obese female schoolchildren in the Al-Khobar area, Eastern Saudi Arabia. J Family Community Med. 2006, 13:65-69.

22. Galobardes B, Smith GD, Jeffreys M, Kinra S, McCarron P: Acne in adolescence and cause-specific mortality: lower coronary heart disease but higher prostate cancer mortality: the Glasgow Alumni Cohort Study. Am J Epidemiol. 2005, 161:1094-1101. 10.1093/aje/kwi147

23. Yang J-H, Weng S-L, Lee C-Y, Chou S-Y, Hsu C-S, Hsu M-I: A comparative study of cutaneous manifestations of hyperandrogenism in obese and non-obese Taiwanese women. Arch Gynecol Obstet. 2010, 282:327-333. 10.1007/s00404-010-1485-2

24. Hazarika N, Rajaprabha RK: Assessment of life quality index among patients with acne vulgaris in a suburban population. Indian J Dermatol. 2016, 61:163-168. 10.4103/0019-5154.177758

25. Kulthanan K, Jiamton S, Kittisarapong R: Dermatology life quality index in Thai patients with acne . Siriraj Med J. 2017, 59:3-7.

26. Capitanio B, Sinagra JL, Ottaviani M, Bordignon V, Amantea A, Picardo M: Acne and smoking. Dermatoendocrinol. 2009, 1:129-135. 10.4161/derm.1.3.9638

27. Bataille V, Snieder H, MacGregor A, Sasieni P, Spector T: The influence of genetics and environmental factors in the pathogenesis of acne: a twin study of acne in women. J Invest Dermatol. 2002, 119:1317-1322. 10.1046/j.1523-1747.2002.19621.x

28. Al Hussein SM, Al Hussein H, Vari CE, Todoran N, Al Hussein H, Ciurba A, Dogaru MT: Diet, smoking and family history as potential risk factors in acne vulgaris - a community-based study. Acta Medica Marisiensis. 2016, 62:173-181. 10.1515/amma-2016-0007 